cation of the disorders which they are studying and who have access to a large data-base of patients. If psychiatrists isolate themselves in the community, progress in the understanding of the neurobiology of psychiatric illness will surely be delayed

Paula H. Salmons

Burton Road Hospital

Dudley, West Midlands

\section{A career in psychiatry}

DEAR SIRS

It is always flattering for an author to be mistaken for one of his characters but Dr Harrington (Bulletin, May 1988, 12, 169-174), has given your readers the impression that their current President as early as 1973 had come to the "harsh conclusion that though psychiatry offers a fascinating and rewarding career, in the future it may be impossible to practise it properly because of lack of staff and resources".

$\mathrm{He}$ is quoting from a contribution which I made to a symposium on 'Planning a District Psychiatric Service'. 'My topic was 'Manpower' and I discussed the possible roles and functions of the consultant - "the ghost in the machine". I contrasted various views of what was desirable as psychiatric manpower with what was actually a vailable at that time. One particular Committee, to which the College contributed, asked for numbers of staff which seemed quite unobtainable. "My" gloomy conclusion was put into the mouth of someone who demanded this lavish staffing as essential. I went on to say "if we accept the harsh realities which I have outlined, what is a psychiatrist's job description and how do we train people for it?"

Interested readers can look this up for themselves. However, Dr Harrington is partly correct: I do believe that psychiatry offers a fascinating and rewarding career.

\section{J. L. T. BIRLEY} President

\section{Reference}

'BirLeY, J. L. T. (1973) The ghost in the machine. In Policy for Action (eds. R. Cawley \& G. McLachlan). Nuffield Provincial Hospitals Trust, Oxford University Press.

\section{Research as a registrar}

DEAR SIRS

Competition for senior registrar posts is becoming increasingly intense in psychiatry, although not as tough as in other specialities such as general medicine and surgery. It seems that the MRCPsych is no longer a passport to a senior registrar post and, when competing for jobs, it is wise to have as many pointscoring attributes as possible. From my own experience, research experience and, better still, publications of some form, seems almost a necessity now and interviewers have realised that just "having a protocol" ready does not always mean that this will result in the work and effort needed to produce a publication.

Having worked in both a non-teaching, countrysituated asylum and a teaching hospital, I have found that trying to get myself involved in some form of research can be quite easy in a teaching hospital where there are consultants who are already involved in projects and enthusiastic in giving advice and ideas to willing registrars. I think that as well as being in the right place, being lucky and working for the right person helps. Some seniors teach and give advice and help that proves to be invaluable in later years but I feel that there should be more emphasis on the teaching of research methodology in the preliminary exam and also the membership (now Part II) so that senior house officers and registrars in psychiatry can be "research minded" at an early stage in their careers and not when they are buying a new suit for an interview!

Finally, mammoth projects demand mammoth amounts of time and effort and a realistic project with clearly defined goals and limits would be wise for a busy registrar. Most of us realise that we will not be winning a Nobel Prize in the near future but some of us will progress from the necessity of undertaking research for job hunting to a more serious and demanding approach.

\section{The Ipswich Hospital Ipswich}

A. Markantonakis

With regard to Dr Markantonakis' letter, research is important for a psychiatric trainee - both to evaluate research and to be involved with research. Research features within the MRCPsych Examination and research methods is recommended to come in MRCPsych courses. The College also organises, and advertises regularly, short courses in research methodology via the College's Research Committee.

Professor A.C.P. Sims

Dean

\section{Erosion of clinical autonomy of RMOs}

\section{DeAR SIRS}

Over the last decade considerable changes in the practice of psychiatry have taken place. No more is the consultant accepted as head of the therapeutic programme by the non-medical professions. This has 